\title{
Uma arte medieval para a invenção e para a memória: a importância do "lugar"
}

M.J. Carruthers

Pode-se considerar este ensaio como uma reflexão mais demorada sobre o antigo mito segundo o qual Mnemósine, a "memória", é a mãe de todas as musas. ${ }^{1}$ Em tal mito, a memória aparece como o início, a matriz da invenção de todas as artes, de toda produção humana, inclusive das idéias. Ele encerra, de modo memorável, a idéia de que a memória e a invenção - o que hoje chamamos "criatividade" - se não são exatamente a mesma coisa, são o que há de mais parecido com ela. Para que possam criar, para que possam exercer o simples ato de pensar, todos os seres humanos necessitam de uma ferramenta ou máquina mental, e essa "máquina” existe nas intrincadas redes de suas próprias memórias.

O vocábulo latino inventio deu origem a duas palavras distintas no inglês moderno. Uma é a palavra "invention" [invenção], que significa "criação de algo novo" (ou, ao menos, diferente). Tais criações podem ser tanto idéias como objetos materiais, inclusive obras de arte, música e literatura. Também é possível referir-se a pessoas que possuem uma "mente inventiva", no sentido de que têm muitas idéias criativas e que normalmente são talentosas para "making" ["criar"], usando o sinônimo do inglês medieval da palavra “composição" ("composition”)

A outra palavra do inglês moderno derivada do vocábulo latino inventio é "inventory” [“inventário"]. Essa palavra refere-se ao armazenamento de materiais diversos, mas não se trata de um armazenamento aleatório: roupas jogadas no fundo de um armário não podem ser consideradas "inventariadas". Inventários devem ter uma ordem. O material inventariado é contado e armazenado em locais dotados de uma estrutura geral que permite a recuperação de qualquer item de maneira fácil e imediata. Esse último requisito também exclui inventários que são volumosos ou indefiníveis demais: pense, por exemplo, em por que é tão difícil encontrar o próprio automóvel em um estacionamento grande.

De fato, embora hoje pensemos em memória como mera reiteração ou repetição, na Idade Média essa memorização era considerada puerilia, uma estrutura necessária porém estritamente basilar, estabelecida na infância. O verdadeiro poder da memória jaz na lembrança ou memoria, que era analisada como uma forma de investigação, a invenção e recriação de conhecimento - na verdade, justamente o princípio pelo qual novos entendimentos são criados pela mente humana. A fim de adquirir tal poder, os indivíduos orientavam sua educação para transformar-se em "bibliotecas" de textos, o que significava dominar os princípios básicos de treinamento da memória: a necessidade de divisio, a necessidade de estabelecer uma localização clara e distinta para cada fragmento de conteúdo memorizado e a necessidade de marcar itens unicamente para sua recuperação segura.

Em fins do século IV, Jerônimo, o patriarca cristão, em carta a um correspondente escreveu que "por meio de leitura atenta e meditação diária, ele deveria tornar-se uma biblioteca para Cristo". ${ }^{2}$ Dois séculos depois, Cassiodorus descreveu um erudito grego 
cego, de nome Eusebius, que havia chegado ao monastério de Cassiodorus em Vivarium. O homem era cego desde a infância, ainda assim "tinha guardado na biblioteca de sua memória [in memoriae suae bibliotheca] tantos autores, tantos livros, que podia certamente dizer a quem estivesse lendo em qual parte do códice poderia achar o que ele tinha mencionado". ${ }^{3}$ Também era do conhecimento de Cassiodorus o exemplo do teólogo Dídimo de Alexandria, um homem cujos comentários das Escrituras eram célebres por sua sutileza e fácil compreensão, e que nasceu cego. Há também exemplos de eruditos do fim da Idade Média, como Tomás de Aquino e Guilherme de Occam, cujos hábitos de leitura e de composição deixavam claro que o objetivo de transformar a mente em uma biblioteca não foi de modo algum perdido em uma época em que livros impressos eram mais abundantes, pelo menos para os eruditos.

Mas como eles eram capazes de fazê-lo? Fica evidente que, embora o feito de homens como Dídimo e Eusebius desperte em Cassiodorus uma quase incredulidade, não é o fato de eles possuírem uma memória tão vasta que o impressiona, e sim o fato de que eles prescindam de olhos para ler os livros. É também digno de nota o fato de o cego Eusebius poder dar a quem lhe pergunte a localização exata de um texto de que ele precise em um códice. Esse feito aparentemente sem sentido e desnecessário nos mostra, na verdade, a razão do sucesso de Eusebius. Sua memória foi moldada de acordo com alguns princípios básicos de memória localizacional ensinados em escolas da Antiguidade, e é esse tema que abordarei a seguir.

$\mathrm{Na}$ teoria da Antiguidade, eximiamente descrita por Aristóteles em seu breve "De memoria et reminiscentia", considerava-se que a memória era o produto final da percepção sensorial, portanto produzida fisiologicamente. ${ }^{4}$ Era um affectus, um "movimento" que efetuava uma mudança no corpo. Essa mudança produzia uma imagem que pode ser vista e lida pelo olho da mente. Seja qual for a informação inicialmente recebida, ela é transformada pelo "sentido interno" em uma imagem visível e gravada como tal na memória. A distinção feita atualmente por alguns psicólogos entre memória "verbal" e memória "visual" não existia para os escritores pré-modernos. Para eles, a memória está sempre contida em imagens, tanto pictóricas como gráficas. Essas imagens assemelham-se muito a letras em uma superfície escrita, cinzeladas em "loci" ou locais físicos do cérebro. Nossa memória é, pois, muito semelhante a um livro, que lemos quando recordamos. Cada informação, codificada como imagem visual, ocupa um lugar específico; pode-se, portanto, ir diretamente até ela e, dessa forma, lembrar-se dela. Os vários sistemas mnemônicos ou de "memória artificial" constituem-se basicamente em arquivar e recuperar esquemas que permitem que a informação textual seja lembrada de maneira a livrar o indivíduo de uma mera reiteração e permitem tanto a lembrança instantânea de uma informação em particular quanto sua livre manipulação, alteração, cotejo e concordância. Em suma, permitem uma memória de acesso aleatório. A capacidade de apenas reproduzir itens de uma série não era considerada memoria, era tão-somente uma capacidade secundária de pouco valor cognitivo. ${ }^{5}$

A extensão de um trecho memorizado em particular é estabelecida pelas condições da capacidade humana de reiteração, que parece ser capaz de lidar com "sete mais-oumenos dois" itens de cada vez na memória ativa. ${ }^{6}$ Os mestres medievais reconheciam essa limitação do poder cognitivo humano e faziam menção a um "conspectus", ou "único olhar" do olho mental como a medida da extensão de uma divisão material armazenada para 
recuperação. Portanto, há Sete Maravilhas do mundo antigo, Sete Virtudes, Sete Pecados Capitais, seis asas do diagrama de Serafim, cada qual com cinco penas. Ensinava-se que, ao memorizar um texto longo, esse fosse dividido em segmentos suficientemente curtos para serem lembrados em um conspectus mental para que os segmentos fossem juntados com sua localização na ordem do texto como um todo. Isso é possível com qualquer ordem prontamente reconstituível, mas é mais comum com números e alfabetos. A localização proporciona o gancho mnemônico que recupera o conteúdo específico do segmento. Quintiliano descreve o resultado: "não importa quão extenso o número [desses segmentos] requerido por nossa memória, todos estão interligados [em sua ordem] como bailarinos de mãos dadas, e não pode haver erro uma vez que unem o que precede ao que sucede". ${ }^{7}$ Devido ao fato de a memória humana de longo prazo ser praticamente ilimitada em sua capacidade, uma quantidade enorme de informações pode ser armazenada dessa maneira - de fato, toda a instrução de um indivíduo pode ser armazenada, prontamente inventariada no depósito da memória.

No treinamento da memória no Ocidente, uma distinção fundamental também era feita entre "memoria verborum", ou memorização literal, palavra-por-palavra, e "memoria rerum", ou a recordação de palavras e idéias principais de um texto, sua "matéria substancial". A isso também se dá o nome de "memoria rerum", a "memória das coisas" e ao ato de lembrar sententialiter ou summatim. Ambos métodos eram considerados tipos legítimos de memorização, cabendo a cada indivíduo a escolha entre um e outro (após passar por instrução elementar no assunto) segundo seu discernimento, capacidade e necessidade. No currículo do trivium, a memorização literal estava particularmente associada à instrução inicial em leitura, o caminho da gramática (para invocar o modelo do trivium como "o ponto de encontro de três caminhos"). Ela era instilada pelo exercício comum de recitatio ou "recitação", como, aliás, continua a ocorrer nos dias de hoje. A "memoria rerum" era aprendida em dois caminhos mais avançados de instrução: a dialética, ou o estudo dos "tópicos' e "locais" do argumento e as relações de proposições e especialmente, o estudo de retórica, a invenção de novas composições. A arte mnemônica, ou o techne de Aristóteles, destinava-se sobretudo às tarefas de investigação e invenção da dialética e da retórica. Portanto, a gramática proporcionava o fundamento sobre o qual se sustentava o trivium; assim, considerava-se que textos memorizados forneciam os modelos e os materiais para novas composições. ${ }^{8}$

Devido ao fato de a memoria ser, de modo tão importante, a base da arte da composição, os objetivos primordiais ao "preparar" material para a memória são flexibilidade, segurança e facilidade de recombinação de assuntos em novos padrões e modelos. Para isso, as tarefas combinadas de divisão e agrupação são essenciais. Um gramático do século IV, Julius Victor, cuja obra exerceu influência particularmente no início da Idade Média (e que, por sua vez, muito deveu a Quintiliano), escreveu que a memoria é “o firme domínio mental de palavras e coisas para fins de invenção". " A Fim de garantir essa segurança, o assunto é primeiramente dividido e ordenado em divisiones ou distinctiones, segmentos ordenados em uma ordem prontamente recuperável, tais como números. Dessa maneira, evitase o erro, pois, se as partes são ligadas de forma segura em ordem seqüencial, (e designadas um, dois, três etc.), nenhuma delas pode ser ignorada ou esquecida. Cada segmento deveria ser "breve" (brevis), não maior do que seu olho mental pudesse abarcar em um único 
olhar ou conspectus. Estabelecer cadeias de elementos na memória permite que uma obra muito extensa - por exemplo, os Salmos ou a Eneida completa - possa ser retida e recuperada de forma segura, tanto em sua ordem original como recombinada e em trechos para obedecer a uma nova composição, simplesmente pelo treino de várias seqüências numéricas. Essas maneiras mnemonicamente eficazes de enumerar os segmentos "breves" de uma obra longa constituem, claro, o princípio por trás da numeração por capítulo e por verso, a exemplo do esquema divisional imposto à Bíblia, presente em comentários de Agostinho e Jerônimo.

Assim, "dividir" o assunto em distinctiones para pregar é mais do que um mecanismo de classificação objetiva; é uma maneira de mesclar e combinar facilmente vários assuntos e ser capaz de "saber onde se está" na composição. Um esquema simples e rigoroso de ordenação é crucial para a prática da oratória, pois ele indica os pontos de princípio (ou os de partida) do orador, de modo semelhante àquele de qualquer esquema, mas com a flexibilidade maior exigida para o desempenho oral. Ele permite ao orador estender-se prontamente sobre um ponto, fazer digressões e fazer incursões retóricas "secundárias" durante o ato de fala porque esse é capaz de sempre ter certeza "de onde está" na composição não como um papagaio (que, ao repetir irrefletidamente, nunca sabe "onde" está)- mas sim como um piloto que entende sua localização com respeito a seu objetivo a partir de marcadores distintivos na água e no horizonte.

O princípio complementar da divisão e da marcação é o agrupamento em um padrão. Cada composição nova pode também ser concebida como um lugar onde assuntos selecionados e lembrados são agrupados. O próprio conceito de leitura em latim baseia-se na noção de "agrupar", sendo que o vocábulo latino legere , "ler", significa na sua raiz etimológica "coletar, agrupar por meio de coleta, colheita ou afins". O verbo grego légo possuía um alcance semelhante de sentidos, desde "colocar" algo a "colocar [coisas] em ordem", donde "agrupar", “escolher", "relacionar", "falar com propósito". ${ }^{10}$ O nome de um tipo essencial e venerável de literatura enciclopédica antiga e medieval faz trocadilho baseado nesses verbos tão próximos: o florilegium, ou "coleta de flores", uma compilação de provérbios, máximas e histórias coletadas em trabalhos anteriores, às vezes citados em sua forma exata (embora em segmentos mnemonicamente "breves"), muitas vezes apenas de forma resumida. A mais conhecida dessas obras por quase toda a Idade Média foi o Dicta et facta memorabilia, de Valerius Maximus, mas há muitos outros exemplos. Na verdade, a enciclopédia pré-moderna é, ela mesma, um tipo de livro de memórias " flores da leitura de alguém" agrupado de forma ordenada para permitir a lembrança rápida e segura relacionada ao ato de estabelecer uma nova composição.

Os esquemas utilizados para organizar a memória variavam enormemente. Podiase escolher entre a planta baixa de uma construção grande, embora totalmente literária (como, por exemplo, a Arca de Noé), as penas das seis asas de um anjo serafim (verfigura 1), a secção de uma casa de cinco andares e cinco cômodos, um mapa-múndi, um diagrama de coluna, as pedras da parede da torre de um castelo, as travessas de uma escada, as fileiras de assentos de um anfiteatro. Jardins também eram populares, jardins medievais, com canteiros de plantas medicinais e árvores frutíferas separados por grama e rodeados por um muro. Indubitavelmente, os jardins eram populares nos mosteiros e, mais tarde, caíram também no gosto dos escritores devido ao Cântico dos Cânticos, um texto preeminente para 
a meditação mística. Várias outras estruturas bíblicas eram usadas com freqüência: o Tabernáculo descrito no Êxodo, o Templo descrito no I Reis, a cidadela de Jerusalém contemplada por Ezequiel e freqüentemente confundida com a Santa Cidade do Apocalipse. ${ }^{11}$ Hoje em dia, jamais pensaríamos em organizar uma enciclopédia tendo como base a planta da Arca de Noé, mas para uma platéia clerical familiarizada com esse texto como nós estamos familiarizados com o alfabeto, por que não? Ela oferece um sítio de composição simples e facilmente ordenável, contém muitos compartimentos úteis com ligações diretas entre si, e pode, portanto, servir como mapa a ser usado na ordenação de assuntos e materiais, agrupando-os no local de uma nova composição das redes de experiências prévias que se tem, incluindo-se aí, naturalmente, todas as experiências acumuladas de livros, música e outras artes. Portanto, no decorrer de uma educação medieval ideal, além de acumular muitos segmentos de textos clássicos e das Escrituras, adquiria-se também um repertório extenso de esquemas pictográficos nos quais colocar tais segmentos, tanto para "armazená-los” como para "agrupá-los” em novas combinações em ocasiões posteriores.

Gostaria agora de examinar brevemente dois desses esquemas dispositivos. A figura 1 mostra uma versão da imagem do serafim (também chamada de querubim, por motivos exegéticos complexos) de Cambridge, Corpus Christi College MS. 66, desenhado em um manuscrito feito em uma fundação cirsteciana na Inglaterra por volta de 1190. Essa figura era inicialmente a pictura que resumia um famoso texto homilético chamado "A tractatus upon the six wings" (De sex aliis) ampla e erroneamente atribuído a Alan de Lille. A obra é mais provavelmente a composição, por volta de 1170, de um prior, Clement, de uma fundação de clérigos em Llanthony em Gloucestershire. O texto "On the six wings" começa com uma meditação sobre a visão do trono divino de Isaías 6, copiado do Livro I, capítulo 2 do comentário moral de São Vítor sobre a Arca de Noé. A segunda metade do tratado tem a ver com a desenho do serafim em si. Oferece uma exposição sucinta, por vezes quase notacional, das lendas sobre as várias asas e penas da criatura angelical, e foi claramente escrito juntamente com o desenho. ${ }^{12}$

Freqüentemente, parte-se do princípio de que uma figura como a número 1 era feita depois que o processo de composição inicial estava completo, essencialmente como um diagrama destinado ao uso do estudante e da platéia. No entanto, quando se lê o tratado "On the six wings", fica claro que, de modo geral, esse texto era de pouca valia exceto para alguém que já conhecia o bastante do assunto a ponto de poder extrapolar sua extrema concisão. Em outras palavras, ele não é útil para um iniciante e sim para alguém já iniciado - não um estudante, mas um professor, especificamente um confessor, um capelão um pregador, pessoas cujos ofícios exigiam a capacidade de falar ex tempore e de modo flexível para várias platéias sobre o vasto tema da penitência. "On the six wings" não é um sermão (não como o classificamos hoje), mas um ars inveniendi, para o qual o próprio estratagema do querubim é básico, sendo as palavras que o acompanham um breve aide-memoire. De fato, a figura logo foi separada do tratado e aparece sozinha com freqüência, dando a entender que o texto era considerado desnecessário para sua função.

A fim de usar um recurso composicional como o Serafim/Querubim, era necessário internalizar a figura, lembrando as divisiones do assunto em ordem, como cabeçalhos de "asas" e sub-cabeçalhos de "penas". Com essa figura em mente (literalmente) podia-se 
prontamente aceder a trinta sermões-meditações, quase suficiente para uma Quaresma inteira, sobre o tema geral da penitência. Cada pregador seria rapidamente capaz de adaptar o esquema a ocasiões específicas de sua própria fala. Adaptar e amplificar um esquema de modelos, afinal, é a maneira pela qual quase todos os sermões medievais são levados a cabo.

A outra imagem (figura 2) é a abertura de um dos mais antigos e melhores manuscritos do Saltério completamente glosado, apresentado neste livro com o comentário de Peter Lombard. Esse manuscrito (Cambridge, Trinity College MS. B 5.4; a outra metade do livro original está na Bodleian Library, Oxford) foi feito em Paris por volta de 1170 para Herbert of Bosham, secretário de Thomas Becket, Arcebispo de Canterbury. As páginas claramente dividem os textos do salmo em breves divisiones da extensão de conspectus, cada uma das quais em um tipo maior. O comentário, em um tipo diferente, circunda esses trechos do texto, pontuados e rubricados de maneira que seus referentes possam ser claramente identificados. Rodeando os comentários principais há ainda margens de outro comentário, e nas margens mais externas, colchetes indicam as fontes dos textos: Agostinho, Cassiodorus, Jerônimo e outros. A página é de fato uma versão preliminar do "hipertexto", seus links e redes projetados para referência e lembrança imediatas. ${ }^{13}$

Mas por que eles eram tão utilizados? A evidência é bastante indireta, mas de fato está presente em relatos de leitura e de composição de eruditos medievais, tais como nos casos a seguir. Em 1330, o frade franciscano Guilherme de Occam, virtualmente isolado da comunidade intelectual da Europa Ocidental pelo Papa João XXII devido a seus ensinamentos que desafiavam o poder papal, foi banido para o convento franciscano de Munique. Passou o resto de sua vida lá. Tendo sido membro de comunidades universitárias em Oxford, Paris e na Itália, onde tivera acesso às melhores bibliotecas da Europa, seu isolamento lhe era penoso, ainda mais que ele não tinha acesso a livros nem meio de obtêlos, pois o Papa havia dado ordens de que nada lhe fosse enviado; tampouco podia receber visitas. A situação de Occam como erudito é um caso extremo que demonstra de modo bastante claro o papel necessário que o treino e transmissão da memória continuava a desempenhar tanto na educação quanto no diálogo erudito durante a Idade Média, mesmo tendo o número de livros se multiplicado enormemente. ${ }^{14}$

Em Munique, Occam compôs um diálogo sobre os limites do poder do papel, uma obra que continuava justamente o debate que o havia colocado em má situação. Na primeira parte de seu Diálogo, o mestre (o próprio Occam) diz a seu pupilo que ele precisa de vários livros e materiais que não consegue obter, um tema que é retomado com freqüência ao longo da obra. Por exemplo, ele se queixa no prólogo à terceira parte de não ter os livros que deseja: "se lhe parece que eu não vou além da superfície do assunto: é o melhor que posso fazer quando não sou capaz, como gostaria, de ter acesso aos livros de que preciso". ${ }^{15}$ Ao que o pupilo responde dizendo que está certo de que esse medo não vai tolher seu mestre. E de fato não tolheu.

O mestre aconselha seu discípulo a extrair e memorizar material de uma gama enorme de fontes; de fato, se ele mesmo não tivesse feito isso quando teve oportunidade, não teria agora esperança de acesso a até os mais fundamentais dos textos, a Bíblia e as coleções de direito canônico. O pupilo pergunta como se pode obter conhecimento sobre um tema como direitos e poderes imperiais. "Conhecimento completo deles, que para 
efeito de compor tratos você se recorda de livros de teologia sagrada, e de ambos tipos de direito, o canônico e o civil, de filosofia moral, e das histórias dos romanos, e especialmente dos imperadores, e dos maiores pontífices, e de outras pessoas, deve ser extraído de modo paciente e solidamente acumulado. Só por esses meios é que tenho esperança de obter a Bíblia e os livros de direito eclesiástico".

Occam não se treinou tendo em mente que um dia pudesse ser exilado, nem era um aluno de escola de província, desprovido de acesso a bibliotecas. Toda sua vida erudita até 1330 transcorreu nas maiores universidades européias, seu círculo era o mais acadêmico de seu tempo. Ainda assim, é evidente que ele lia para memorizar e que na composição ele se baseava de maneira extensa nos recursos de sua biblioteca mental. Ele pede àqueles com acesso a uma biblioteca que "completem" e "preencham as lacunas" de sua obra. Ele se desculpa por apenas "tocar a superfície" nas suas análises e exposições do assunto, pois se tivesse acesso ao material poderia expandir plenamente o que havia acumulado antes em sua memória. ${ }^{16}$ Essa obra incompleta e prefacial composta de memória ocupa quinhentas e cinqüenta e uma páginas manuscritas de tamanho fólio com material que certamente não é de natureza elementar.

A situação de Occam não era, em absoluto, única no fim da Idade Média. Em 1382, o teólogo dissidente John Wyclif foi condenado por vinte e quatro de suas opiniões e enviado de Oxford, onde havia ensinado e vivido por muitos anos, rumo ao exílio. Foi confinado na pequena paróquia de Lutterworth, cerca de oitenta quilômetros ao norte. Lá, prosseguiu com uma produtiva rotina de trabalho, a despeito do fato de que não tinha uma biblioteca à disposição exceto por alguns livros levados pelos poucos amigos que ousavam visitá-lo. Sua produção desse período, que inclui muitos sermões, um extenso comentário de trechos do Evangelho e muitas obras polêmicas, está repleta de citações de muitas fontes, que excedem em muito as que seriam possíveis a julgar pelos poucos livros que tinha à mão. Tal como o exilado Occam, Wyclif evidentemente viu-se forçado a consultar principalmente a biblioteca de sua própria memória. ${ }^{17}$ A extensão de suas citações torna ainda evidente que sua biblioteca mental era de dimensões consideráveis. Sem dúvida, para os eruditos modernos a maior parte dessas citações parece ser do tipo e extensão daquelas encontradas nos florilegia. De fato, isso confirma o que sabemos de outras fontes sobre o modo pelo qual se ensinava aos alunos a memorizar suas leituras, ou seja, como conjuntos de trechos, marcados e codificados em arquivos prontamente recuperáveis e por referências cruzadas, cada uma delas da extensão de um simples olhar do "olho da mente". Tomando como base a miríade dessas divisiones básicas e resumos em suas memórias, todos do tamanho de uma entrada de um florilegium, é que teólogos universitários como Occam e Wyclif compuseram a maior parte dos tractatus filosóficos.

Relatos medievais do verdadeiro processo de composição de novos trabalhos são poucos e esparsos, embora existam. Eles oferecem mais um olhar revelador sobre como se ensinava os acadêmicos a ler e a programar suas mentes para reter e recordar o que haviam lido, como a "biblioteca da memória" era acessada e consultada. A imagem mais citada é a de uma página escrita, retangular, com linhas e colunas, sobre a qual se escrevia como que usando um estilo (ou seja, uma haste) mental, do mesmo modo como se escreve um livro material, com rubricas e pontuação, glosas com referências a outros textos e até notas e 
marcadores nas margens. Na Antigüidade, Quintiliano aconselhava aos alunos de gramáti$\mathrm{ca}$, aprendizes de leitura, que memorizassem sempre seus trechos dos textos usando as mesmas tabuletas de cera em que os haviam escrito antes, como se estivessem seguindo os rastros (vestigia) de uma caça. "Segue então sua memória por um caminho, como se caminho houvesse, e vê com seu olho da mente não só as páginas mas quase que as linhas: então, quando fala, age quase como uma pessoa que lê em voz alta."18 A memória treinada é, portanto, descrita como extremamente parecida como páginas retangulares escritas, mesmo em uma época (e isso é o mais notável) em que os livros eram escritos em rolos, e não em códices. ${ }^{19}$

Esse conselho pedagógico teve vida longa no Ocidente. No século XII, o mestre de Paris, Hugo de Saint Victor, aconselhava seus noviços que "é de grande valia que, ao fixar uma memória imagética ao ler livros, nos esforcemos a fim de imprimir em nossa memória não apenas o número e a ordem dos versos ou das idéias, mas que ao mesmo tempo imprimamos a cor, o formato, a posição e a localização das letras onde vimos [o trecho] escrito, em que parte, em que posição (no alto, no meio ou no final) o vimos [na página], que observemos de que cor eram as letras ou a superfície ornamentada do pergaminho." ${ }^{20}$ Dois séculos e meio depois, conselho semelhante partiu de outro mestre francês, Jacques Legrand: “aprende melhor quem aprende de livros com iluminuras, pois as diversas cores garantem a recordação de diferentes linhas [do texto] e, conseqüentemente, do assunto que se quer aprender de cor." ${ }^{21}$ De fato, a primeira descrição detalhada que se tem do processo de memorizar vem do Rhetorica ad Herennium, do século I a.C. , que enfatiza que os alunos deveriam sempre memorizar seus trechos usando sempre o mesmo livro, pois livros diferentes causariam confusão de imagens e desativaria a memória que se tinha das palavras. ${ }^{22}$

O modelo da página de memoria não se limitou, naturalmente, a noviços ou alunos de nível elementar. Concluirei com dois relatos de hábitos de composição de eruditos maduros, na verdade dois dos maiores autores medievais, Tomás de Aquino e Dante Alighieri. Ambos relatos salientam que a composição é o resultado final da leitura deliberada, concentrada e meditada que transforma a memória em uma verdadeira biblioteca. Bernardo Gui, biógrafo de Tomás de Aquino, descreve como esse ditava aos seus secretários "como se uma grande torrente de verdade estivesse jorrando de Deus por meio dele. Não parecia buscar algo que já não fosse de seu conhecimento; ele parecia simplesmente permitir que sua memória liberasse seus tesouros. (...) Ao deparar-se com uma dificuldade, ajoelhava-se e rezava e, ao voltar ao texto que escrevia ou ditava, costumava notar que seu pensamento havia se tornado tão claro que parecia mostrar-lhe, como se fosse um livro, as palavras de que necessitava". Quando Tomás de Aquino ditava, suas palavras "fluíam tão claramente que era como se o mestre lera em voz alta de um livro que tivesse diante de si." ${ }^{23}$

Portanto, a página da memória também serve como a página sobre a qual se criam novas composições. O uso que Dante faz do tropo de que a mente é um livro é sobejamente conhecido e abunda em sua obra, mas uma menção é, talvez, particularmente reveladora. No início de La vita nuova, ele escreveu que "In quella parte del libro de la mia memoria dinanzi a la quale poco si pottrebe leggere, si trova una rubrica la quale dice: Incipit vita nuova. Sotto la quale rubrica io trovo scritte le parole le quali è mio intendimento 
d'assemplare in questo libello; e se non tutte, almeno la loro sentenzia." 24 Dante descreve, então, palavras escritas em sua memória em grandes marcadores de prágrafos. Como é bem sabido, ele se apresenta nesse livro tanto como o escriba como comentarista de poemas que já havia composto. Para Dante, o autor era também o leitor, alguém que lembra o texto, o editor e o reautor de seu próprio texto em construção, e no processo de composição Dante tinha uma imagem mental de seu texto, escrito em sua memória como páginas com texto, rubricas e pontuação.

Assim, considerava-se que a ornamentação de um texto europeu manuscrito era parte integrante de um texto que fosse útil para seus leitores. As ilustrações, as cores, as divisões de pontuação, as diferenças de escrita entre o texto principal e as glosas, todo o conjunto da página formava um instrumental para sua leitura, mas não apenas ou nem mesmo primeiramente como auxílio na compreensão do conteúdo. Como muitos historiadores já apontaram, a decoração presente nas páginas de alguns livros devocionais do fim da Idade Média não só não têm absolutamente nada a ver com seu conteúdo como parecem mesmo ser totalmente opostos a ele. A decoração das páginas de livros manuscritos, mesmo de livros como esses, está na verdade relacionada à divisão e à organização dos assuntos na página para fins de memorização e meditação; atende a necessidades cognitivas. E a prova mais evidente de que isso é verdade reside não apenas no fato de que várias pessoas comentaram exatamente sobre sua utilidade à época, mas também no fato de que a maioria dos autores talentosos e criativos da época compunham suas novas obras em seus olhos da mente lançando mão de esquemas organizacionais que reproduziam as páginas decoradas de seus livros. 


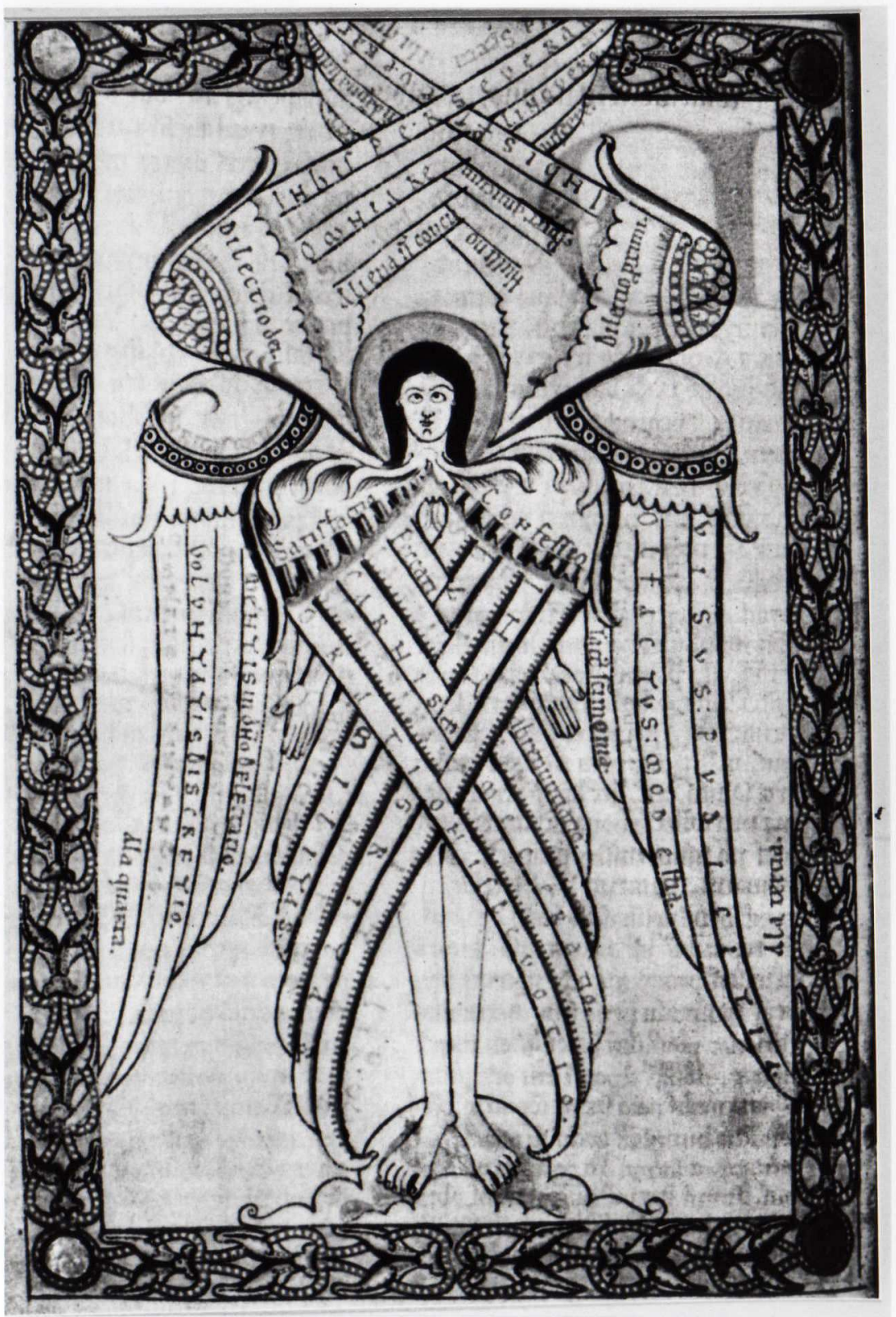

Figura 1:

Diagrama do "Serafim", composto provavelmente por volta de 1170 como uma figura verbal em um tratado do prelado Clemente para os cônegos de Llantony em Gloucestershire.

Manuscrito inglês da Abadia de Sawley (Cisterciense), por volta de 1190. Cambridge, Corpus Christi College MS. 66, p. 100. 


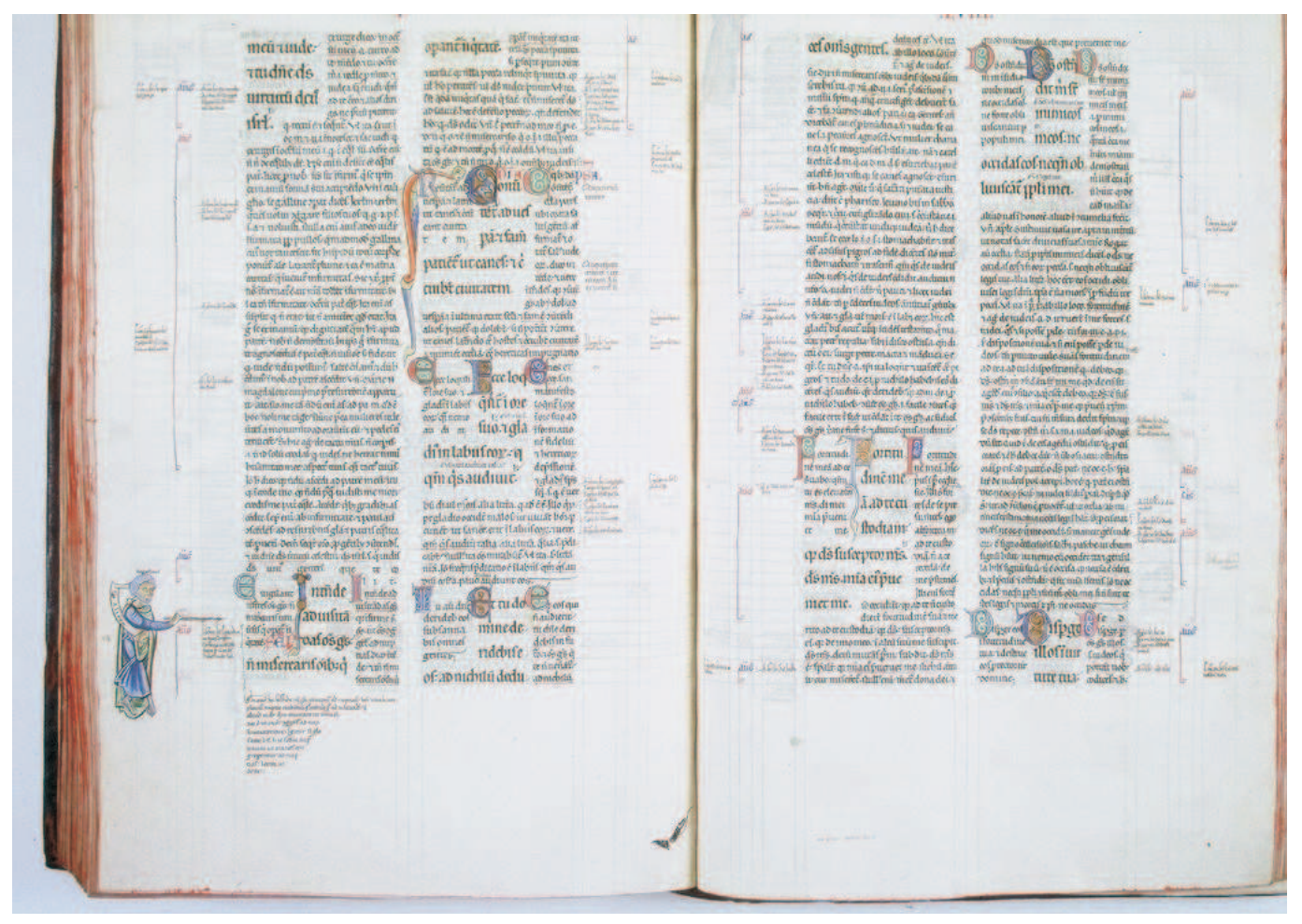

Figura 2:

Saltério (Salmo 58) glosado por Peter Lombard, confeccionado em Paris por volta de 1170 para Herbert de Bosham. Cambridge, Trinity College MS. B. 5.4, ff. 14v147. O texto foi concebido como um conjunto de segmentos ou "divisões" dispostas separadamente em uma estrutura de "células" mentais, compartimentos que são delimitados pelos diversos tipos de escrita, pelas iniciais e pelas margens.

${ }^{1}$ Uma versão deste ensaio foi publicada anteriormente sob o título Ars inveniendi, ars memorativa: Visualization and Composition in the late Middle Ages," em: Il senso della memoria, Atti dei Convegni Lincei 195 (2003): 29-42. Roma: Accademia Nazionale dei Lincei.

2 "Lectioneque assiduo, et meditatione diuturna, pectus suum bibliothecam fecerat Christi": Jerome, Epistulae lx.10, Patrologia latina XXII.595.

3 "Hic tantos auctores, tantos libros in memoriae suae bibliotheca condiderat, ut legentes probabiliter admoneret, in qua parte codicis quod praedixerat invenirent.” Cassiodorus, Institutiones I. 5. 2 Utilizei a versão de R.A.B. Mynors, Oxford, 1937. Cassiodoro menciona o exemplo de Dídimo, o cego, neste mesmo trecho. Em seu Life of St. Anthony, [Vida de Santo Antônio] livro fundamental dos primórdios do monasticismo, São Atanásio comenta a alentada memória do santo, da qual se valia em vez de usar livros: ver cap. 2-3. Quando menino, Santo Antônio recusou-se a aprender a ler e, de acordo com a obra supracitada, aprendeu as Escrituras somente por meio oral. A impressão causada por essa história em Santo Agostinho precipita a crise que ele descreve Confessiones, Livro VIII. 
${ }^{4}$ Descrevi a análise de Aristóteles em The Book of Memory, [O Livro da Memória] Cambridge, 1990, cap. 2; ver as notas do livro para mais referências. Como demonstrei, além do relato de Aristóteles no tratado "De memoria et reminiscentia," em Parva naturalia, os comentários de Ibn Sina e Ibn Rushd tanto sobre De anima quanto de Parva naturalia são criticamente importantes para que se compreenda como estudiosos do fim da Idade Média compreendiam a natureza da lembrança.

${ }^{5}$ Uma autoridade importante foi Alberto Magno, autor de Liber de memoria et reminiscentia, um comentário sobre a obra de Aristóteles, tractatus 2, cap.3. Nessa obra, lembrança ou reminiscentia se define como investigação racional (ou seja, investigação que conscientemente se serve de um método ou esquema) e que se distingue de iterato addiscens, aprendizado por repetição.

${ }^{6}$ Este limite numérico foi confirmado em um experimento psicológico de G. A. Miller, "The magic number seven, plus or minus two: some limits on our capacity for processing information,” [O número mágico sete mais ou menos dois: alguns limites da nossa capacidade de processar informações] Psychological Review 63, 1956, pp. 81-97

7 "Ita, quamlibet multa sint quorum meminisse oporteat, fiunt singula conexa quodam choro [ne erre]nt coniugentes prioribus consequentia"; Institutio oratoria XI. 2. 20; cf. XI. 2. 37-38, no qual existem conselhos semelhantes. Neste artigo citei a edição latina de M. Winterbottom dos Oxford Classical Texts, 2 vols., Oxford, 1970, exceto neste caso, um ponto de notória relevância, no qual ofereci uma leitura dos manuscritos corrigidos do séc. XV. Ver a nota de D. A. Russell em sua tradução desta passagem para a Loeb Classical Library, vol. 494 (Quintilian, The Orator's Education, Books 11-12), Cambridge MA, 2001.

${ }^{8}$ Deve-se ter em mente que meditatio era o vocábulo utilizado em tratados latinos de retórica para designar as etapas da composição: ver, por exemplo, Quintiliano, Institutio oratoria X. vi. A “premeditação" dos temas a serem abordados era considerado essencial para o sucesso da oratória e Quintiliano observa que isso depende totalmente do poder da memória de cada um. Discuti com mais profundidade algumas maneiras pelas quais o treinamento de retórica e as primeiras práticas de meditação influenciavam-se mutuamente em M. Carruthers, The Craft of Thought, Cambridge, 1998.

9 "Memoria est firma animi rerum ac verborum ad inventionem perceptio"; Ars rhetorica, cap. 23, C. Halm (ed.), Rhetores latini minores, Leipzig, 1863, p. 440, linha 11.

${ }^{10}$ Definições do Oxford Latin Dictionary, Oxford, 1982, s.v. lego² e do A Greek-English Lexicon, Oxford, 1968.

${ }^{11}$ Discuti exemplos de todas essas figuras organizacionais em The Craft of Thought. entre elas, há trabalhos de Hugo de Saint Victor ( A Arca de Noé), Bede (o Templo de Salomão), Gregório o Grande (Templo de Ezequiel), Richard of St. Victor e Adam of Dryburgh (o Tabernáculo), e vários escritores monásticos que trataram das "hortas" e "jardins" da alma. Um exemplo em especial se destaca: Richard of Fournival (morto por volta de 1260), um cônego da catedral de Amiens, discorreu sobre um currículo de leitura, organizando seus tópicos como um jardim de livros dispostos como se estivessem plantados em canteiros: ver The Craft of Thought, pp. 273-274.

${ }^{12}$ Para mais análises deste tratado e para uma tradução do texto, ver The Medieval Craft of Memory: An Anthology of Texts and Pictures, org. M. Carruthers e J. Ziolkowski, Philadelphia, 2002 , pp. 83- 102. Sobre o desenvolvimento do diagrama, ver L. F. Sandler, The Psalter of Robert de Lisle in the British Library, London, 1983. O uso evidente do diagrama por São Bernardino de Siena em suas pregações é demonstrado por L. Bolzoni, "Predicazione e arte della memoria: un quaresimale di Bernardino da Siena e l'immagine del Serafino," em R. G. Kecks, org. Musagetes: Festscrift für Wolfram Prinz, Berlin, 1991, pp. 179-195.

${ }^{13}$ Para o desenvolvimento do formato de livro glosado em Paris e para uma avaliação desse manuscrito, ver C. F. R. de Hamel, Glossed Books of the Bible and the Origins of the Paris Booktrade, Cambridge, 1984.

${ }^{14}$ Baseei-me no relato sobre a vida e a obra de Occam por J. Miethke, Ockhams Weg zur Sozialphilozophie, Berlin, 1969.

${ }^{15}$ Citações do Dialogus de Occam: ver Miethke, pp. 121-125 e The Book of Memory, pp. 156- 159.

${ }^{16}$ Segundo Occam, "de prefatis me nullatenus intromittam: maxime cum ad libros necessarios non valeam peruenire." Ao que seu pupilo responde, “Timor non te retrahat memoratus." Não há versão moderna dos Dialogus de Occam: utilizei a edição de 1494 impressa em Lyon (um facsimile foi publicado em Londres em 1982), na qual a citação aparece na folha 181. 
${ }^{17}$ Há vários relatos de boa qualidade sobre a vida e o pensamento de Wyclif, entre os quais A. Kenny, Wyclif, Oxford, 1986, e A. Hudson, The premature reformation: Wycliffite texts and Lollard history, Oxford, 1988.

18 "Sequitur enim uestigiis quibusdam memoriam, et uelut oculis intuetur non paginas modo sed uersus prope ipsos, estque cum dicit similis legenti”; Quintilian, Institutio oratoria, XI. 2.32; tradução de D.A. Russell. ${ }^{19}$ Ver H. Caplan, Of Eloquence, Ithaca, N.Y., 1970, pp. 196- 246, e J. P. Small, Waxed tablets of the mind, London, 1997.

${ }^{20}$ Do prefácio de Hugo de Saint Victor à crônica de história bíblica, citada da minha tradução em Carruthers e Ziolkowski, The Medieval Craft of Memory, p. 38.

${ }^{21}$ Minha tradução de Jacques Legrand, Archiloge sophie, ed. E. Beltran, Paris 1986 , p. 145.

${ }^{22}$ The Book of Memory, p. 263. Não é possível que Hugo tivesse conhecido o texto de Quintiliano diretamente, fato que reafirma tanto a longevidade da antiga pedagogia como a importância de técnicas práticas para a sobrevivência e adaptação de fontes escritas.

${ }^{23}$ Citações da Vida de Tomás de Aquino por Bernardo Gui, capítulos 15-16 e 32, traduzido em K. Foster, Biographical Documents for the Life of St. Thomas Aquinas, Oxford, 1949.

24 “Naquela parte do livro da minha memória, antes da qual pouco poderia ler-se, há uma epígrafe que diz Incipit vita nova [Começa a vida nova]. Sob tal epígrafe se encontram escritas as palavras que é meu propósito reunir na presente obrinha, senão em sua integriudade, ao menos substancialmente." [Vida Nova, tradução Carlos Eduardo Several, Lisboa: Guimarães Editores, 1993, p. 7] La vita nuova I, L. Pietrobono (ed.), Firenze, 1964. O comentário de Dante sobre palavras escritas em suas memórias "sotto maggiori paragrafi" está no final da parte II.10. 